\title{
Objetivos e fins de um sistema de observação regional
}

\section{Objectives and purposes of regional observation system}

\author{
Andreas Dittmar Weise ${ }^{1}$; Jürgen Wilhelm Philips ${ }^{2}$
}

\section{Resumo}

Um sistema de observação regional é um instrumento para o planejamento municipal. Com base no Sistema de Informações Geográficas e no banco de dados deste sistema, podem-se identificar áreas sensíveis, frente ao desenvolvimento municipal, nos municípios e apoiar o processo de soluções sustentáveis. O banco de dados contém informações sobre a infraestrutura, a situação real do Plano Diretor, a utilização das áreas no município e os imóveis e seus usuários. Em conjunto com outros programas é possível interpretar estes dados e fazer um planejamento mais eficiente para o futuro do município. Exemplos como à cidade de Leipzig, na Alemanha, demonstram que estes sistemas têm aplicação sobre os diversos departamentos dentro dos municípios, onde poderão surgir novas possibilidades de utilização. Um dos problemas poderão ser o custo da coleta de dados, a manutenção e atualização dos dados.

Palavras-chave: Sistema de observação regional. Sistema de informações geográficas. Planejamento municipal.

\begin{abstract}
A regional observation system is a tool for municipal planning. With a base in Geographic Information System and through a database that system can identify problem areas in the municipalities and support the process of sustainable solutions. The database contains data about the infrastructure, the real situation of the land utilization plan, the use of the areas in the municipality and the buildings and their users. Together with several other programs it's possible to interpret this data and make a good planning for the future of the city. Examples like the city Leipzig, Germany, demonstrate that these systems have application to the various departments within the municipalities, where there may be create new possibilities for use. One of the problems may be the cost of data collection, maintenance and updating of data.
\end{abstract}

Key words: Regional observation system. Geographic information system. Municipal planning.

\section{Introdução}

A política de desenvolvimento urbano no Brasil é influenciada pelo crescimento demográfico, aumento na procura por habitações, aumento na concorrência econômica e de localização, e necessidade de maior mobilidade. Além disso, o impacto do consumo de recursos e emissão de poluentes, diferentes estilos de vida e sistemas econômicos também são claramente observados nas cidades.

O desenvolvimento urbano brasileiro é um tema em constante discussão devido à necessidade de lidar com o grande crescimento econômico, com a especulação imobiliária e, inclusive, com a redução no consumo de recursos e na poluição. Deste modo, o novo modelo de desenvolvimento das cidades busca atingir o objetivo de um "desenvolvimento urbano sustentável" de forma mais direta.

\footnotetext{
1 Professor da Universidade Federal de Santa Maria, Departamento de Engenharia de Produção e Sistemas; mail@adweise.de

2 Professor da Universidade Federal de Santa Catarina, Departamento de Engenharia Civil; jphilips@gmx.net
} 
Investimentos são pré-requisitos para o desenvolvimento de cidades e regiões, porém isto também envolve riscos sobre estes investimentos, que precisam ser observados e reduzidos dentro das possibilidades.

Um desenvolvimento sustentável de uma cidade necessita, além de investimentos, de uma infraestrutura adequada. Para isso, é importante observar o trânsito, assim como o desenvolvimento residencial, comercial e industrial, e as características locais físicoambientais e sociais que podem interferir na dinâmica do município.

Isto gera grandes desafios à política de desenvolvimento urbano, tais como:

- acesso rápido a informações atuais, detalhadas e relevantes do planejamento urbano;

necessidade de uma visão global das avaliações e consequências espaciais das decisões vinculadas ao atual planejamento de construção e de fatores sociais, econômicos, ecológicos e estruturais-urbanos; e

reconhecimento precoce de tendências de desenvolvimento de forma que seja possível implantar instrumentos efetivos de controle para que erros de desenvolvimento sejam evitados.

Dessa forma, o objetivo principal do presente estudo consiste em descrever o desenvolvimento de um sistema de observação regional com seus objetivos e conteúdos.

Por meio de uma observação atualizada, é possível determinar áreas de alta necessidade de atuação, nas quaisocorrem defeitos no desenvolvimento habitacional, assim como a observação geral sobre o desenvolvimento da cidade. Com isso, a prefeitura consegue agir de maneira mais decisivamente para resolver problemas e, ao mesmo tempo, tem uma visão mais geral sobre os planejamentos e execuções de diversas secretarias do município.

\section{Metodologia}

Esse tópico é reservado para detalhar o delineamento da pesquisa, apresentar o método, as técnicas, procedimentos e instrumentos de coleta de dados. Vergara (2010) divide as pesquisas em dois critérios básicos: quanto aos fins e quanto aos meios. Os fins de uma pesquisa definem a finalidade ou o motivo de uma pesquisa.

A presente pesquisa se caracteriza, quando aos fins, como uma abordagem bibliográfica com finalidade descritiva.

Estudos descritivos têm a intenção de expor características de uma população ou de um fenômeno, sem o compromisso de explicálo, embora sirva de base para tal explicação (VERGARA, 2010).

Quanto aos meios, este trabalho pode ser definido como estudo de caso. Essa categoria de pesquisa possibilita o estudo exaustivo e profundo de um indivíduo, um grupo ou uma organização, ou ainda, um conjunto de organizações. Possui grande flexibilidade (LAKATOS; MARCONI, 2010). Por outro lado, isso impede a generalização das conclusões (GIL, 2002).

\section{O sistema de observação regional}

O Sistema de Observação Regional da cidade de Leipzig, Alemanha, é um sistema de informação geográfica (ALEMANHA, 2008) que registra as estruturas espaciais e as mudanças visuais baseadas nos imóveis. O sistema é utilizado como ferramenta de apoio para as tarefas de planejamento urbano (AFHELDT; SIEBEL; SIEVERTS, 1987) e como um instrumento de planejamento e de tomada de decisão política e administrativa. Desta forma, o departamento de planejamento urbanístico da cidade é responsável pelo sistema. 


\section{Construção e gestão do banco de dados}

O banco de dados de um sistema de observação regional é formado a partir do levantamento total da estrutura dos imóveis residenciais, comerciais e industriais; do espaço disponível para utilização no município; e da divisão da área urbana em quadras da cidade.

Os dados dos bairros nos quais foi identificado um desenvolvimento com altas taxas de crescimento deverão ser atualizados. Além disso, o sistema deve conter dados oficiais, tais como os do Instituto Brasileiro de Geografia e Estatística (IBGE), no Brasil, bem como em outras bases de dados existentes. Ainda devem abranger dados regionais com as áreas de construção do município e as informações estatísticas sobre municípios vizinhos - o que permite a análise de dados fora dos limites da cidade. Porém, isto faz com que se a coleta de

Tabela 1: Conexão ao transporte público dados gere altos custos.

\section{O conteúdo do banco de dados}

A coleta de dados poderá ser baseada em uma lista de perguntas sobre infraestrutura, situação no Plano Diretor (AFHELDT; SIEBEL; SIEVERTS, 1987), informações sobre a situação atual da quadra, áreas abertas e a edificação em si, bem como informações básicas como: CEP, rua, nome do proprietário, número do lote e da quadra, bem como os números de imagens aéreas, e número dos mapas e das cartas, etc. Assim, se dará importância à demografia, ao mercado de trabalho e a outros dados.

Quanto à infraestrutura, esta se divide em duas partes: conexão ao transporte público (Tabela 1) e conexão no sistema de ruas e de rodovias (Tabela 2).

\begin{tabular}{|c|c|c|}
\hline Meio de transporte & Número de linhas & Distância ao centro da quadra \\
\hline \multicolumn{3}{|l|}{ Ônibus urbano } \\
\hline \multicolumn{3}{|l|}{ Ônibus interurbano } \\
\hline \multicolumn{3}{|l|}{ Metrô } \\
\hline Bonde e/ou trem urbano & & \\
\hline
\end{tabular}

Tabela 2: Conexão no sistema de ruas e rodovias

\begin{tabular}{|c|c|c|c|}
\hline Tipo de conexão & Quantidade & Rua alternativa & Área com baixa quantidade de trânsito \\
\hline Rua principal & & & \\
\hline Rua secundária & & & \\
\hline
\end{tabular}

O fundamento do Plano Diretor encontrase na Lei 10.257 (BRASIL, 2001) que também é denominada de Estatuto da Cidade em seu próprio texto. Conforme artigo $1^{\circ}$ da lei, esta tem a função de regulamentar os artigos 182 e 183 das da Constituição Federal de 1998 (BRASIL, 1988), nos quais são estabelecidas normas de ordem pública e de interesse social que regulam o uso da propriedade urbana em prol do bem coletivo, da segurança e do bem-estar dos cidadãos, bem como do equilíbrio ambiental.

Com esta lei o Plano Diretor passou a ser obrigatório para as cidades:

1.com mais de 20 mil habitantes - o que abarca 4.172 dos 5.561 municípios brasileiros; 
2.que fazem parte de regiões metropolitanas; e

3.turísticas ou que têm grandes obras que colocam o meio ambiente em risco ou que gerem mudanças na região, tais como a implantação de hidrelétricas.

Desta forma, a lei incluiu praticamente todos os municípios que tiveram ou foram afetados por desenvolvimentos econômicos e urbanísticos no passado, presente e no futuro. Porém, para um sistema de observação regional, é necessário que o município tenha um Plano Diretor atualizado e funcionando em todos os bairros do município. Para o banco de dados do sistema, seriam necessárias algumas informações do Plano Diretor, como a descrição de cada área no município (Tabela 3 ) e a situação das construções e dos projetos (Tabela 4). A forma de tratamento de dados deverá interoperável, ou seja, pode ser de forma tabular ou vetorial, conforme a necessidade do banco de dados. Neste artigo, as informações serão vetoriais.

Tabela 3: Descrição no Plano Diretor

\begin{tabular}{ll}
\hline Área residencial & Áreas de órgãos públicos \\
\hline Área comercial & Áreas de preservação permanente \\
\hline Área industrial & Outros \\
\hline
\end{tabular}

As designações de áreas demonstradas na Tabela 3 podem variar conforme a denominação do Plano
Diretor do município. Além disso, as classificações podem ser organizadas de formas diferentes

Tabela 4: Construção real e projetos

\begin{tabular}{lcc}
\hline Tipo & Sim/Não & Número do projeto \\
\hline Sem construção e sem projeto aprovado & & \\
Com construção e sem projeto & & \\
Sem construção e com projeto aprovado & \\
Com construção e com projeto & \\
\hline
\end{tabular}

As informações sobre a ocupação das quadras demonstram se ainda existe espaço para futuros projetos ou se somente existe a possibilidade de substituir imóveis já existentes como forma de oferecer novos imóveis.

No caso de ainda existirem espaços sem construção, é importante que se saiba o endereço do terreno, a utilização atual, o tamanho e os dados de um GIS. Também devem ser determinados e inseridos no banco de dados os tipos de construção que ocupam a quadra, conforme apresentado na Tabela 5. 
Tabela 5: Tipos de construção

\section{Imóveis comuns}

\begin{tabular}{llll}
\hline Casa Apartamento & Loja & Escritório
\end{tabular}

Construção de esquina

Construção aberta

Construção fechada

\section{Imóveis especiais}

Hospital Hotel Shopping Center Parque de lazer

Construção na esquina

Construção aberta

Construção fechada

Tabela 6: Exploração de áreas

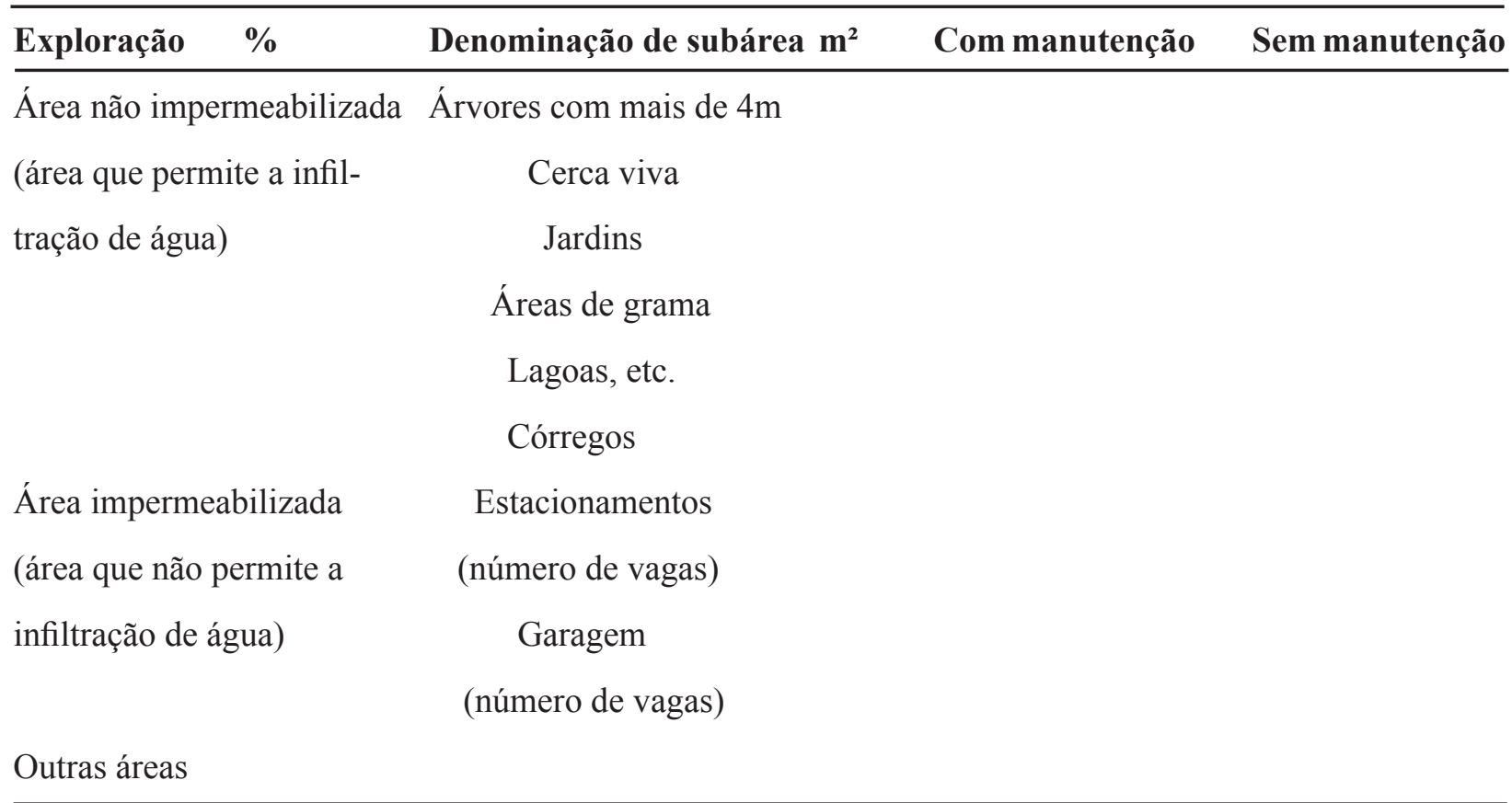

Uma divisão temporal histórica - que divida o desenvolvimento até 1920, de 1920 até 1964, de 1964 até 1994 e de 1995 até hoje - orientada nas grandes mudanças políticas ocorridas no passado recente do Brasil seria necessária. Outra característica a ser coletada é o número de andares, conservação, padrão, distância da rua e informações sobre a utilização dos imóveis. No caso de imóveis desocupados, são importantes as seguintes informações:

•nível de desocupação - total ou parcial; e

•desocupação de prédio reformado.

As áreas disponíveis do município são áreas 
que atualmente não tem construções. Podem ser terrenos que já foram utilizados ou terrenos que nunca foram utilizados para a construção. O Plano Diretor somente deveria ser estendido depois que estes terrenos sem construção tiverem sido utilizados. Para a análise e controle da situação de áreas abertas, é importante observar e coletar informações sobre a exploração das áreas na quadra, conforme a

Tabela 6.

Também são importantes dados sobre a situação ambiental, a coleta de lixo, a existência de empresas de produção, de plantas (árvores com importância), etc.

A coleta de dados sobre as edificações como altura e área construída - é um pouco mais complicada (AFHELDT; SIEBEL; SIEVERTS, 1987), contudo um bom banco de dados deve conter estas informações. Isto porque uma classificação geral é complexa e praticamente inútil.

A propriedade da edificação deverá ser separada entre:

-privada;

•órgãos públicos;

-empresas públicas;

• organizações não-governamentais;

-grandes empresas; e

-desconhecida.

Junto às informações da propriedade são coletados os dados da edificação, do terreno e localização da edificação. Estes dados geralmente são:

•área do terreno;

•número de andares;

•área total da edificação;

•número de apartamentos; •número de vagas na garagens; e

•padrão da edificação.

O tipo da utilização - própria, alugada e não conhecida - também é um dado importante para o banco de dados. A localização do imóvel dentro do Plano Diretor também faz parte destes dados. Além disso, outros dados importantes são os relacionados ao tipo da construção. Para facilitar a coleta de dados, estes serão classificados simplesmente conforme o tipo de construção, tais como: madeira, tijolo ou concreto (pré-fabricada ou normal).

O sistema também permite a inclusão de vários bancos de dados, bem como as informações sobre a demografia e o mercado de trabalho (SOMMER, 2008). Com os dados demográficos, pode-se demonstrar a distribuição da população por sexo e idade para cada bairro ou até mesmo cada quadra. Nas áreas comerciais e industriais, e no restante da área municipal, são importantes dados sobre quantidade de funcionários e localização dos locais de trabalho.

Interpretação de dados relevantes do planejamento

Por meio da combinação do banco de dados com um sistema cartográfico, é possível atualizar rapidamente as bases de decisão, proporcionanado uma visão profunda nas estruturas urbanas e nos processos. Por isso, o usuário conecta-se ao banco de dados com um mapa digital, que é a base para a localização dos imóveis em cada cidade. A combinação do mapa com o banco de dados oferece a possibilidade de (ALEMANHA, 2008):

-mapas altamente complexos de informação ou de planejamento que atendam pedidos de informações políticas e de planejamento gerados com o uso de comandos simples;

-ajuste do conteúdo do mapa de inserção rápida de novas variáveis ou de dados atuais a 
qualquer momento; e

- editar e atualizar cada registro no mapa, de forma ágil e facilitada.

\section{Estrutura de um sistema de observação regional}

A estrutura de um sistema de observação regional urbana inicia-se com um problema de planejamento e objetiva auxiliar nas decisões de planejamento político. O sistema consiste em um banco de dados multifinalitário que proporciona informações diretas do banco de dados e, também, interpretações destes dados, tais como comentários sobre bairros específicos. Para cada bairro é possível uma observação conjunta dos problemas e das potencialidades. A base para a delimitação destas áreas são as construções existentes no bairro, relacionadas à história ou específica na quadra. Por outro lado, tem-se ainda a demarcação subjetiva dos bairros realizada pelos seus residentes (áreas de identificação), que é orientada apenas parcialmente por fronteiras da área administrativa (ALEMANHA, 2000).

Além disso, o sistema disponibiliza tabelas, gráficos e mapas de planejamento, que possibilitam a análise, a visualização e a apresentação dos dados. Com essa estrutura os usuários têm as seguintes vantagens:

- fácil uso de todos os componentes do sistema de observação regional - suportado por computadores comuns no lugar de trabalho - sem a necessidade de conhecimentos especiais para a extração das informações desejadas;

-possibilidade de extensões com alguma portabilidade no fundamento de mapas para temas específicos;

-possibilidade de troca de dados com outros programas de mapas e de gráficos, assim como com a administração de cidades que utilizam o sistema Sicad (AED-SICAD, 2008); e -baixo custo com a utilização de software existente (tais como Excel) para a gestão e para a atualização de dados, bem como a compra de um programa de baixo custo para a visualização destes.

A importância de um sistema de observação regional se baseia em três grupos de usuários (BERGMANN, 2008):

•cidadãos;

-investidores; e

- o próprio município.

Aos cidadãos, o sistema pode oferecer informações gerais sobre o município, projetos atuais, busca de endereço, visualização da localidade, dentre outros serviços (BERGMANN, 2008).

Ainda conforme Bergmann (2008), para os investidores, este sistema fornece informações mais específicas que para os cidadãos. Ao investidor, o sistema provê informações, por exemplo, sobre as ofertas mais atuais de áreas industriais e, até mesmo, uma pré-seleção de possíveis áreas que atendam suas exigências.

Já para o município, a vantagem está nas informações sobre cidadãos e investidores, além de informações de todos os outros departamentos incluídos no sistema, a plataforma de comunicação e o acesso aos dados gerais e geográficos, bem como dados sobre economia, ambiente e planejamento (BERGMANN, 2008). Para os investidores bem como aos cidadãos não estão todas as informações acessíveis, que o sistema contempla.

\section{Futuro dos sistemas de observação regional}

Atualmente, sistemas de observação regional são utilizados como ferramenta do departamento de planejamento municipal em várias cidades, 
dentre as quais Leipzig na Alemanha, onde o uso do sistema também está sendo estendido a outros departamentos (LÜTKE DALDRUPP, 2000). A utilização do sistema de observação regional evita custos resultantes do recolhimento de dados repetidos. Em contrapartida, uma aplicação ampla colabora para o desenvolvimento contínuo do banco de dados decorrente das atualizações exigidas e realizadas pelos usuários. A atualização do banco de dados inclusive pode ser proveniente dos serviços de estatística e da justiça eleitoral.

Exemplos da utilização do sistema no município de Leipzig

A seguir, é apresentada a identificação de áreas problemáticas, com a alienação de fins habitacionais, as mudanças de números de habitações, de terrenos comerciais e de industriais.

\section{Alienação de fins habitacionais}

Uma área na qual ocorrem alienações para habitações é apontada como área que merece atenção em Leipzig. Desde 1990, foram utilizados mais de 660.000 metros quadrados de área residencial para outros fins. Quase 50\% desta utilização para outros fins é destinada a escritórios. Com um sistema de observação regional, pode-se definir a extensão e a distribuição regional do uso para outros fins - e assim o potencial risco de um deslocamento de uso residencial - nos bairros.

Com base nessas declarações, recomenda-se a criação de um novo Plano Diretor que limite este desenvolvimento. Para isto, também pode ser utilizado o sistema para determinar a estrutura disponível.

\section{Mudanças de números de habitações entre} 2000 e 2004

A destruição de habitações antigas e a criação de novas são problemáticas para os municípios, pois, para o crescimento sustentável de um município, é necessário conhecer os bairros nos quais se perde ou se ganha área habitacional. Entre 2000 e 2004, a diferença entre os bairros foi extrema. O bairro Lausen-Grünau perdeu 513 habitações enquanto no bairro de Wiederitzsch foram criadas 790 (VESER, 2006).

Figura 1: Mudanças nos números de habitações (VESER, 2009).

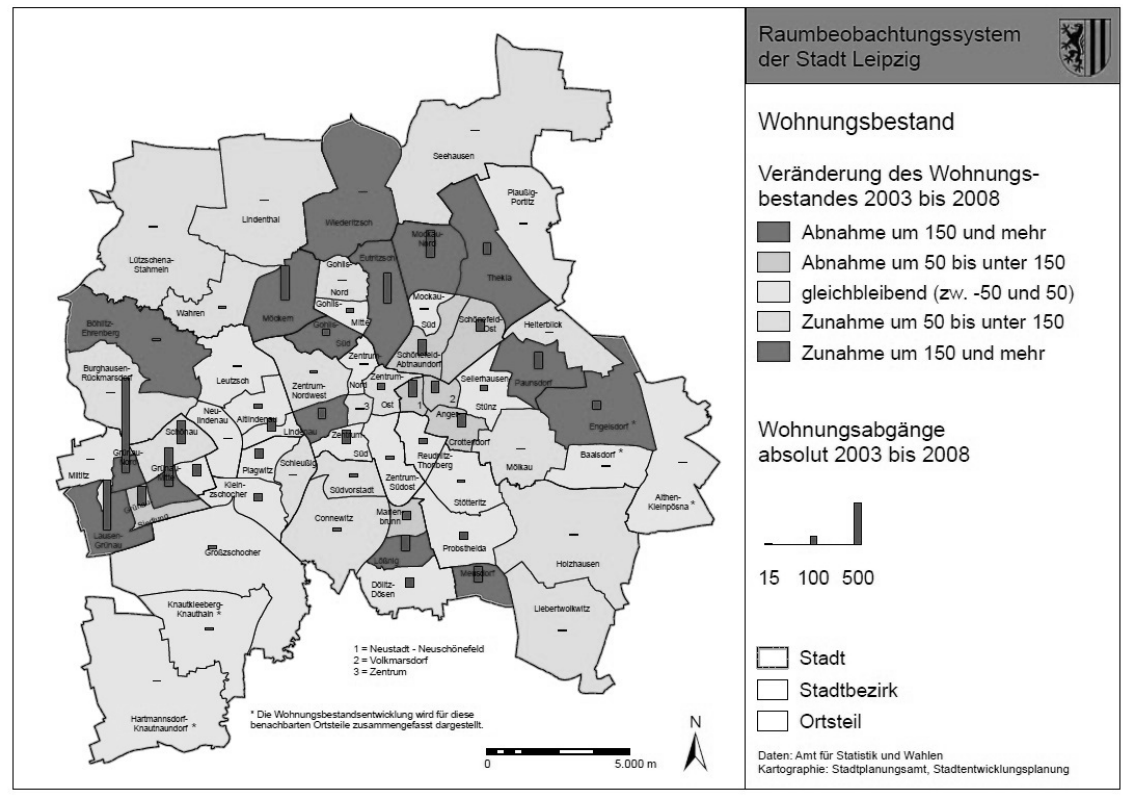


$\mathrm{Na}$ Figura 1, as barras demonstram as saídas de habitações do mercado imobiliário. A cor vermelha escuro demonstra os bairros com a maior diminuição de habitações enquanto a cor azul escuro apresenta os bairros com o maior crescimento por meio a construção de novas habitações. Com isto, é possível determinar que o desenvolvimento no município não é igual e comparável entre os bairros.

\section{Terrenos comerciais e industriais}

Da mesma forma que se faz necessário o controle do desenvolvimento dos imóveis residenciais, também é importante o controle do desenvolvimento dos imóveis comerciais e industriais do município. É preciso que se realize um controle constante sobre a escassez de imóveis em uma parte do município e excesso em outra.

Com o uso do sistema, é possível verificar as áreas nas quais o município cresce normalmente, onde se tem casos de especulação imobiliária e onde se tem uma diminuição de empresas comerciais e industriais. Desta forma, o município consegue, por meio de atividades políticas, influenciar o desenvolvimento na cidade e criar um equilíbrio entre os bairros,gerando o desenvolvimento sustentável de longo prazo.

$\mathrm{Na}$ cidade de Leipzig é visível que a maior quantidade de negócios estão localizadas no centro da cidade (azul) com áreas relativamente pequenas, conforme se pode observar na Figura 2. Em outros bairros existe um número menor de negócios, porém com áreas maiores (Figura 3). Isto significa que no centro foram negociadas muitas lojas enquanto que fora do centro são executados desenvolvimentos industriais e comerciais, como shopping centers, que precisam de mais espaço.

Figura 2: Mudanças no volume de vendas de áreas residencial em relação à quantidade total de negócios imobiliários entre 1997 - 2003 na cidade Leipzig (ALEMANHA, 2005)

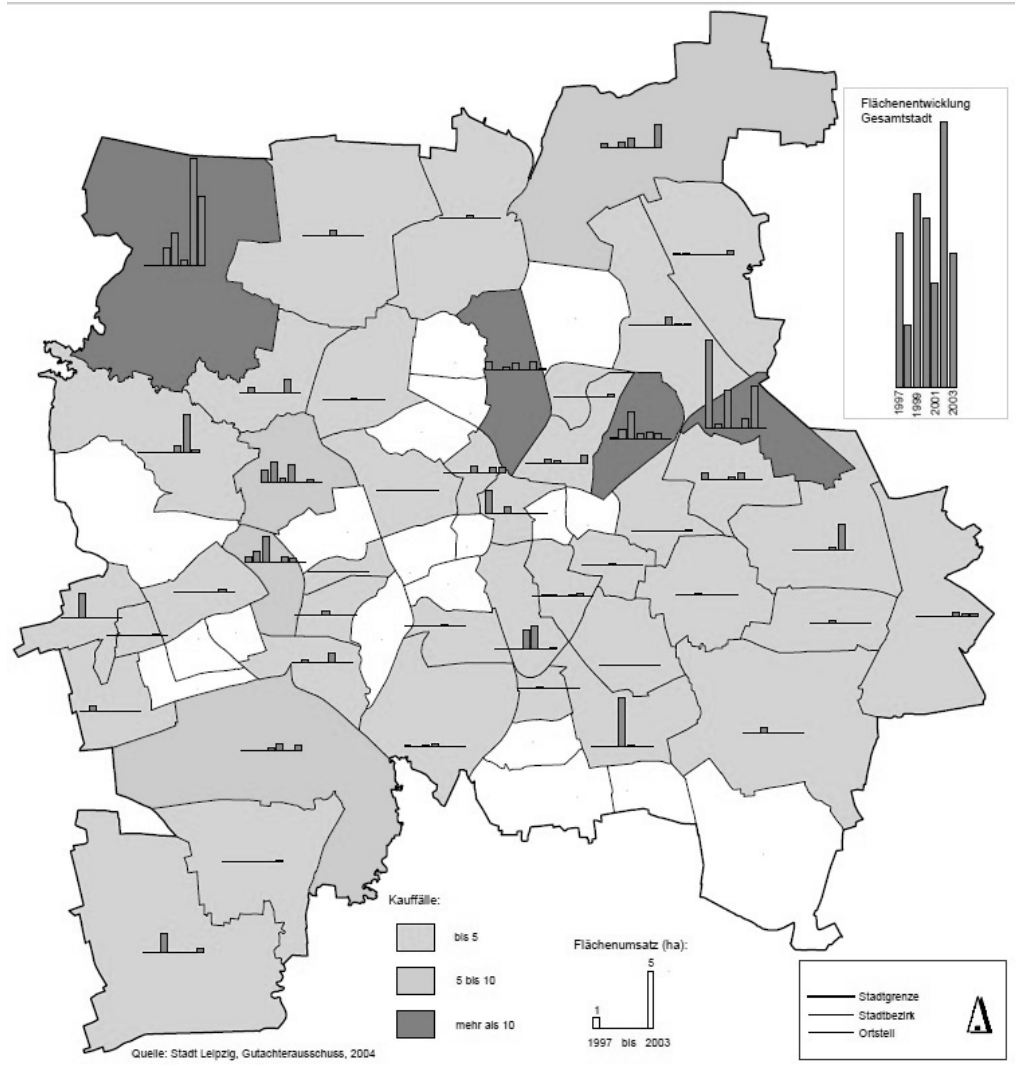


Figura 3: Mudanças no volume de vendas de áreas comerciais e industriais em relação à quantidade de negócios imobiliários entre 1997 - 2003 na cidade Leipzig (ALEMANHA, 2005)

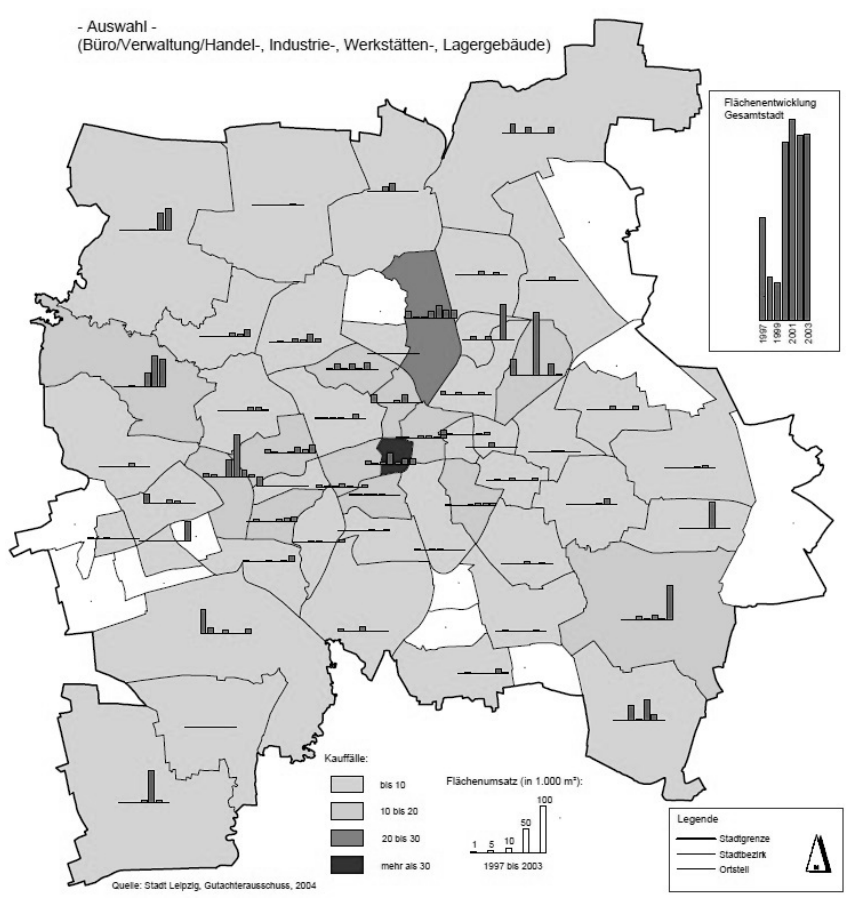

As barras de cor vermelha (Figura 4) demonstram armazéns; e a branca, outros tipos de construção não áreas industriais; a cor rosa, oficinas; a cor azul, especificados.

Figura 4: Imóveis comerciais e industriais - áreas vendidas em função do tipo do imóvel (ALEMANHA, 2005)

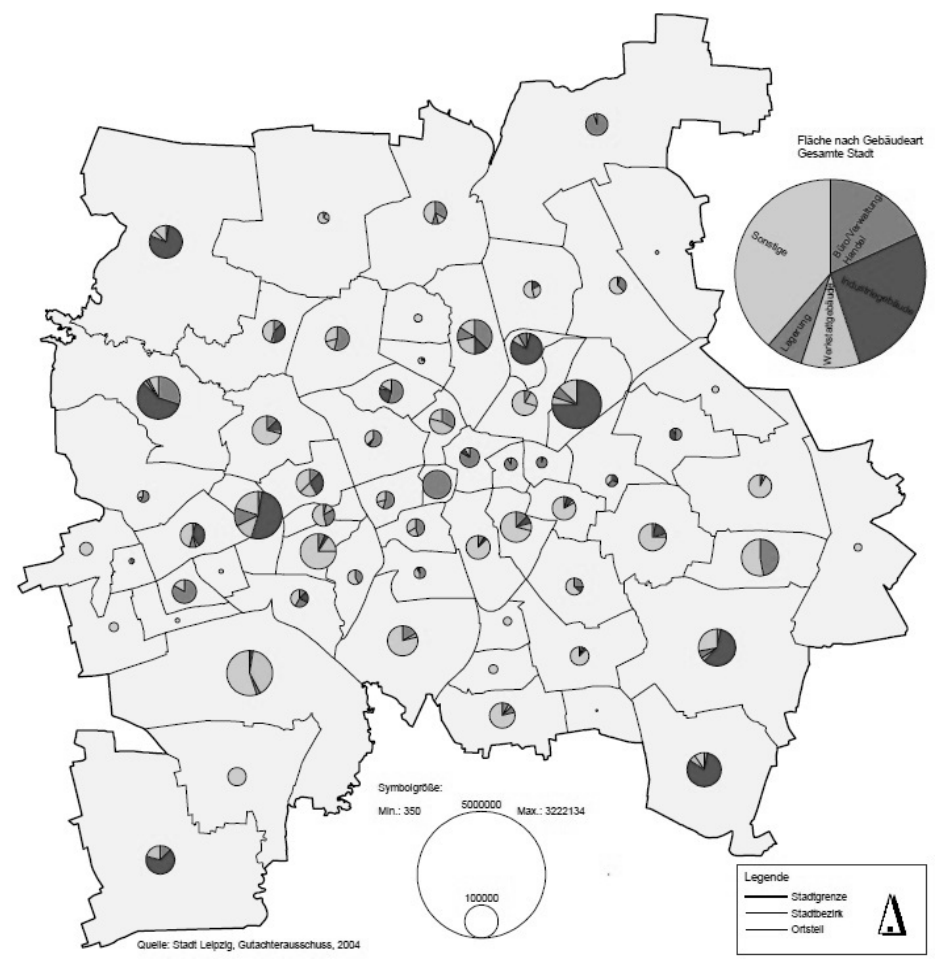




\section{Conclusões}

O sistema de observação regional é um sistema de informação geográfica que registra e visualiza as estruturas espaciais e as mudanças com base nos imóveis. É utilizado para apoiar tarefas de planejamento como um instrumento de tomada de decisões políticas e administrativas. O banco de dados inclui informações básicas como endereço; número do lote; informações avançadas sobre a infraestrutura; transporte público e individual; situação legal da área no Plano Diretor; tipos de imóveis e a ocupação destes; áreas abertas, áreas seladas e não seladas; e, finalmente, dados sobre a edificação, seja sobre a construção em si, a situação legal ou sua exploração. A inclusão de dados demográficos do município e do mercado de trabalho pode demonstrar a distribuição da população por sexo e idade para cada bairro, e até mesmo cada quadra. Nas áreas comerciais e industriais e no restante da área municipal, são importantes dados sobre quantidade de funcionários e localização dos lugares de trabalho.

A interpretação destes dados é importante para o planejamento de modo que a combinação deste banco de dados com mapas facilita a interpretação dos dados e a identificação de áreas problemáticas. Para tanto, é necessário criar um banco de dados multifinalitário que fique disponível para todos os usuários e os departamentos. A inclusão de outros bancos de dados com informações sobre economia, demografia e mercado de trabalho aumenta as possibilidades de utilização do sistema. Um sistema único facilita a troca de informações e a identificação de áreas problemáticas. O sistema de observação regional de Rhein Neckar (2008) demonstra como pode ser estruturado um sistema que permite, inclusive, a utilização via internet.

A utilização do sistema de observação regional evita custos resultantes do recolhimento de dados repetidos. Em contrapartida, uma ampla aplicação estimula o desenvolvimento contínuo do banco de dados, decorrente das atualizações exigidas e realizadas pelos próprios usuários. A atualização do banco de dados também pode ser proveniente dos serviços de estatística e da justiça eleitoral.

Por enquanto, sistemas deste tipo ainda não são utilizados no Brasil. Vários municípios brasileiros tem um sistema de gerenciamento municipal informatizado, como Blumenau, Curitiba ou São Paulo, que pode ser uma base para a criação de sistema de observação regional.

Contudo, no futuro, deve-se verificar o uso, as formas de coleta de dados, a migração ou inclusão de dados de outros sistemas ou banco de dados, as atualizações permanentes e a relação custobenefício de cada tipo de sistema.

\section{Referências}

AED-SICAD. ArcFM UT. Disponível em: <http://www. aed-sicad.com/index.php/utilities.html $>$ Acesso: 1 de abr. 2008.

AFHELDT, H.; SIEBEL, W.; SIEVERTS, T. Gewerbeentwicklung und Gewerbepolitik in der Grossstadtregion. Bleicher: Gerlingen, 1987.

ALEMANHA. Bundesamt für Bauwesen Und Raumplanung Bundesinstitut für Bau-, Stadt- und Raumforschung. Raumbeobachtung.de. Disponível em: $<$ http://www.raumbeobachtung.de/>. Acesso: 12 abr. 2008.

BERGMANN, E. Interkommunales Gewerbe- und Kompensationsflächenmanagementaufinterkommunaler Basis im Jade-Weser-Raum (Landkreis Friesland): modellvorhaben. Disponível em: $<$ http://www.bbr. bund.de/nn_23558/DE/Forschungsprogramme/ ModellvorhabenRaumordnung/ Forschungsfelder/ InnovativeProjekteRegionalentwicklung/ Modellvorhaben/NachhaltigeSiedlungsentwicklung/ Jade-Weser-Raum/LangfristigeGewerbeKompensation. html>. Acesso em: 23 Abr. 2008.

BRASIL. Constituição Federal. 1988. Disponível em: $<$ http://www.planalto.gov.br/ccivil 03/Constituicao/ Constitui\%C3\%A7ao.htm>. Acesso em: 10 jan. 2008.

. Estatuto da cidade: Lei 10.257. 10 de julho de 2001. Disponível em: <http://www.planalto.gov.br/ CCIVIL/leis/LEIS_2001/L10257.htm>. Acesso em: 7 abr. 2008. 
GIL, A. C. Como elaborar projetos de pesquisa. 4. ed. São Paulo: Atlas, 2002.

LAKATOS, E. M.; MARCONI, M. A. Fundamentos de metodologia cientifica. 7. ed. São Paulo: Atlas, 2010.
ALEMANHA.
LEIPZIG.
Glossar: raumbeobachtungssystem. Disponível em: <http:// www.leipzig.de/de/buerger /stadtentw/buergerbet/ glossar/01710.shtml>. Acesso em: 15 jan. 2008.

_. Gewerbflächenentwicklung: monitoring zum stadtentwicklungsplan gewerbliche baufächen 2005. Disponível em: <http://www.stadt-leipzig.de/ imperia/md/content/61_ stadtplanungsamt /bericht_ gewerbeflaechenentwicklung.pdf $>$. Acesso em: 15 jan. 2008.

LÜTKE DALDRUPP, E. Informationsvorlage zum Raumbeobachtungssystem. Leipzig: Stadtplanungsamt Leipzig Abteilung für Stadtentwicklungsplanung, 2000.

$\begin{array}{lrr}\text { RHEIN } & \text { NECKAR. } & \text { Raumbeobachtungssystem. } \\ \text { Disponível } & \text { em: } & <\text { https://www.ssl-id.de/ }\end{array}$ raumbeobachtung-rhein-neckar.de/RBS-red/FLA/flash. html>. Acesso em: 23 abr. 2008.

ALEMANHA. STADTPLANUNGSAMT LEIPZIG. Stadtentwicklungsplan "Wohnungsbau und Stadterneuerung - Stadtteilpass Ost, Leipzig. 2000.

SOMMER, H. Raumbeobachtungssystem Rhein-Neckar. Disponível em: <http://www.bauforum.rlp.de/transfer/ details.php?sid=e5819cb6a7031bf81a9aaaccc3d36bda\& table $=$ link\&id=111\&log=1>. Acesso: 23 abr. 2008.

VERGARA, S.C. Métodos de pesquisa em administração. 4. ed. São Paulo: Atlas, 2010.

VESER, J. Anforderungen na komunale Wohnungsmarktbeobachtung. Disponível em: <http:// www.bbr.bund.de/nn_22702/DE/ForschenBeraten/ Wohnungswesen/ Wohnungsmarkt/Wohnungsmarkt beobachtung/kommWOB/Veser_mh,templateId $=$ raw, property=publicationFile.pdf $/$ Veser_mh.pdf $>$. Acesso em: 2 fev. 2010.

Recebido em 10 Julho, 2010 - Received on July 10, 2010.

Aceito em 27 Janeiro, 2011 - Accepted on January 27, 2011. 